\title{
Gestational diabetes, comparison of women diagnosed in second and third trimester of pregnancy with non GDM women: Analysis of a cohort study
}

\author{
ANDREA HUIDOBRO ${ }^{1}$, ANDREW PRENTICE ${ }^{2}$, TONY FULFORD ${ }^{2}$, \\ CARMEN PARODI ${ }^{3}$, JAIME ROZOWSKI ${ }^{3}$
}

Universidad Católica del Maule, Chile.

2Public Health and Nutrition Department, London School of Hygiene and Tropical Medicine, UK.

${ }^{3}$ Departamento de Nutrición Pontificia Universidad Católica de Chile.

Recibido el 7 de Agosto de 2009, aceptado el 22 de Enero de 2010.

Correspondencia a: Andrea Huidobro. Av San Miguel 3605

Escuela de Medicina, Universidad Católica del Maule. Talca. Chile.

Teléfono: 5692196618 Fax: 5671203435 E-mail: Ahuidobro@ucm.cl

\begin{abstract}
Pregnant women are normally screened for Gestational diabetes (GDM) at week 24 of pregnancy. However some women develop the disease later on their pregnancies. No study has analyzed women developing GDM later in pregnancy. Objective: To analyze data on a cohort study and compare women diagnosed with GDM in second and third trimester of pregnancy with women without GDM. Results: GDM women diagnosed during their first two trimesters of pregnancy were older $(p=0.0008)$ and had higher body mass index (BMI) $(p=0.0007)$ than non GDM women. However, the only risk factor in women diagnosed in their third trimester of pregnancy was having first degree relatives with type $2 D M$ and this was independent of age and BMI (OR of 2.7, 95\% CI 1.2 - 6.0). Conclusions: Women who develop GDM in their second trimester of pregnancy have known risk factors for diabetes mellitus such as age and higher BMI, however, the only recognised risk factor between non GDM women and women developing GDM late in pregnancy is family history of type 2 DM. Two populations of GDM may exist and future studies should focus on analysing short and long term complications of these women to support the need to diagnosed and treat them all.
\end{abstract}

(Rev Med Chile 2010; 138: 316-321).

Key words: Diabetes Mellitus, gestational, incidence, risk factors.

\section{Diabetes gestational, comparación entre mujeres diagnosticadas en el segundo y tercer trimestre del embarazo con mujeres sin diabetes gestacional: Análisis de un estudio de cohorte}

La pesquisa para diabetes gestacional (DG) se realiza normalmente en la semana 24 de embarazo. Sin embargo, muchas mujeres desarrollan la enfermedad más tardíamente durante el embarazo. No hay estudios analizando DG en tercer trimestre del embarazo. Objetivo: Analizar los datos de una cohorte para comparar mujeres con DG diagnosticada en segundo y tercer trimestre del embarazo con mujeres sin DG. Resultados: Las mujeres diagnosticadas en los primeros dos trimestres del embarazo eran mayores $(p=0,0008)$ y tenían mayor indice de masa corporal (IMC) $(p=0,0007)$ que las mujeres sin DG. El único factor de riesgo en mujeres diagnosticadas en el tercer trimestre del embarazo fue tener antecedentes familiares 
de DM, lo cual fue independiente de la edad e IMC (OR: 2,7, 95\% CI 1,2 - 6,0). Conclusiones: Mujeres con DG diagnosticada en el segundo trimestre del embarazo tienen distintos factores de riesgo que mujeres diagnosticadas más tardiamente. Es posible que existan dos poblaciones de DG según el período de diagnóstico, por lo que debiera estudiarse si las complicaciones de estos dos subgrupos justifican el diagnóstico $y$ tratamiento de ambos.

$\mathrm{T}$ he diagnosis of gestational diabetes mellitus (GDM) has been proved to be critical when treating conditions associated to adverse consequences to mother and child. In this regard GDM has been associated with a greater risk of hypertension and Caesarean section and abortion ${ }^{1}$. Newborns from GDM mothers have a higher incidence of being large for gestational age (macroso$\mathrm{mia}^{2,4}$, being born preterm ${ }^{4}$, of hypoglicaemia and jaundice ${ }^{3,6}$, of admission to a neonatal unit ${ }^{3}$ and perinatal death ${ }^{2,5}$. GDM has also been associated with long term complications in the mother and in the child. Mothers with previous GDM have higher incidence of type 2 diabetes mellitus ${ }^{7}$ while their children have higher risk of developing adult obesity and other chronic non-transmissible diseases $^{8}$. However, not all the studies on GDM support these associations and the discrepancies could be explained by the different methods to diagnose GDM. In this regard, some studies use $75 \mathrm{~g}-1 \mathrm{~h}$ OGTT while others use $100 \mathrm{~g}$-2h OGTT, some centres use $200 \mathrm{mg} / \mathrm{dl}$ cut-off to diagnose $\mathrm{GDM}^{9}$ while others agree with the WHO recommendations of a $140 \mathrm{mg} / \mathrm{dl} \mathrm{cut-off}{ }^{10}$. Moreover, some centres test al women while others test only women with recognised risk factors, and some centres test only in second trimester o pregnancy while others retest during the third trimester. These differences in the approach to diagnosing GDM explain not only part of the different prevalences in GDM but also variability in short- and long-term risk associated with GDM. Lowering the cut-off glycaemia or testing more frequently or later in pregnancy would result in both, higher prevalence of GDM but lower risk associated with the diagnosis. To our knowledge there are no studies comparing GDM women diagnosed in second and in third trimester of pregnancy with women who do not develop GDM. This comparison would help to know if these women share the same risk factors and would enlighten us regarding the benefit of testing all women in late pregnancy. The primary objective of this study was to compare women diagnosed with GDM in second with those diagnosed in third trimester of pregnancy in terms of recognised risk factors for GDM. Secondary objectives were to compare risk factors and delivery outcome between GDM in second and third trimester of pregnancy with non-GDM women.

\section{Research designs and Methods}

Women who belonged to a cohort of pregnant women who attended antenatal care at two polyclinics associated to Catholic University Hospital, Santiago, Chile, were followed from January 2002 to June 2003. All pregnant women who attended to antenatal care before week 20 of a single foetus were enrolled into the study after signing informed consent. Women were dated between weeks 24 to 28 and between week 34 to 36 of pregnancy for anthropometric measurements and blood tests. Follow up was completed in 50 women who developed GDM in the first two trimesters of pregnancy and 27 women diagnosed with GDM in the third trimester of pregnancy, along with 327 non-GDM women (70\% of the initial cohort). Gestational Diabetes was diagnosed or ruled out according to the classification of the Chilean Ministerial Norms based on the American Diabetes Association ${ }^{11}$ plus a second oral glucose tolerance test (OGTT) made to all women during the third trimester of pregnancy to completely rule out the development of diabetes. While data on pregnancy were prospectively recorded, delivery data were extracted from the clinical records. Women in the study attended to routine obstetric appointments and the obstetricians were aware of the study and had access to the GDM diagnosis.

To study recognised risk factors for GDM, we analyzed age, pre-pregnancy weight according to mother's report at recruitment, educational level, marital status, number of previous pregnancies, 
antecedents in previous pregnancies including abortion, stillbirth, macrosomia, intra uterine growth retardation (IUGR) and congenital malformations. We also analyzed weight, height, fasting glycaemia and insulinaemia, insulin resistance calculated through Homeostasis Modelling Assessment (HOMA), all measured at recruitment in all the mothers. Weight and height were measure by the same nutritionist with the patient in underwear in an electronic SECA balance with height rod. Glycaemia was measured through glucose oxidase method while insulinaemia was measured through radioimmunoassay technique. HOMA values of 2.5 or over were considered as insulin resistance. To analyze complications associated to GDM we measured gestational age at delivery, type of delivery, weight and height of the newborn, Apgar score of the newborn and presence of metabolic and trauma complications in the newborn and/or the mother.

In the statistical analysis variables are presented as percentages if they are categorical or means and standard deviation (mean $\pm \mathrm{SD}$ ) if they are continuous. To show the precision of the data standard error (SE) or 95\% confidence interval are presented. Association of recognised risk fac- tors for GDM and characteristics on delivery with GDM were analyzed with Chi Squared, ANOVA and Student T Test as appropriate. We analyzed general data on the whole cohort, followed by the analysis of differences on risk factors and delivery data between non-GDM and GDM groups and separately for non-GDM with each group of GDM women diagnosed in second and third trimester of pregnancy. It was not necessary to transform variables since all of them were normally distributed. Independence of associated variables was tested with logistic regression using stepwise analysis. Statistical analyzes were performed using STATA 9.0 Software.

Ethical approval from Catholic University of Chile and London School of Hygiene and Tropical Medicine were obtained.

\section{Results}

The cohort consisted in women 16 to 44 years old with a mean of $30.8 \pm 5.0$ years. Characteristics of the two groups of GDM and non-GDM women are shown in Table 1.

The comparison between non-GDM women

Table 1. Characteristics of GDM women diagnosed during the second trimester of pregnancy, women diagnosed in third trimester of pregnancy and non-GDM women

\begin{tabular}{|c|c|c|c|}
\hline Variable & $\begin{array}{c}\text { GDM }_{1} \\
(n=50)\end{array}$ & $\begin{array}{c}\text { GDM }_{2} \\
(n=27)\end{array}$ & $\begin{array}{l}\text { Non-GDM } \\
(n=327)\end{array}$ \\
\hline \multicolumn{4}{|l|}{ Educational Status } \\
\hline Iliterate \% (n) & 0 & 0 & $0.31(1)$ \\
\hline First school (\%) (n) & $42(21)^{*}$ & $22.2(6)$ & $24.8(81)$ \\
\hline High School (\%) (n) & $58.0(29)^{*}$ & $77.8(21)$ & $74.9(245)$ \\
\hline Age (years) & $33(31.5-34.5) \dagger$ & $31(29.0-33.0)$ & $30.5(29.9-31.0)$ \\
\hline $\mathrm{BMI}_{0}\left(\mathrm{~kg} / \mathrm{m}^{2}\right)$ & $26.6(24.9-28.3)^{*}$ & $25.3(23.7-26.9)$ & $25.1(24.6-25.5)$ \\
\hline $\mathrm{BMI}_{1}\left(\mathrm{~kg} / \mathrm{m}^{2}\right)$ & $28.6(27.4-29.7) \dagger$ & $26.8(25.2-28.4)$ & $26.6(26.2-27.0)$ \\
\hline No Previous pregnancies & $1.5(1.0-2.0) \dagger$ & $1.1(0.4-1.8)$ & $0.95(0.8-1.1)$ \\
\hline $\mathrm{PIH}$ or colestasis in previous pregnancy \% (n) & $32.7(16)$ & $25.9(7)$ & $24.2(79)$ \\
\hline Abortion (n) & $0.5(0.1-0.8)$ & $0.5(0.0-1.1)$ & $0.3(0.2-0.4)$ \\
\hline Gycaemia (mg/dL) & $82.9(79.5-86.2) \dagger$ & $78.6(75.8-81.4)$ & $76.5(75.6-77.5)$ \\
\hline HOMA & $3.4(0.9-6.0) \dagger$ & $1.6(1.4-1.8)$ & $1.7(1.6-1.8)$ \\
\hline
\end{tabular}

${ }^{*} \mathrm{p}<0.05$ when comparing with non-GDM. $+\mathrm{p}<0.01$ when comparing with non-GDM. BMI. Pre-pregnancy body mass index.

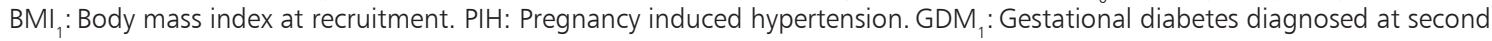
trimester of pregnancy. $\mathrm{GDM}_{2}$ : Gestational diabetes diagnosed at third trimester of pregnancy. 


\begin{abstract}
Table 2. Characteristics of mothers and their deliveries comparing those who developed GDM in the second trimester of pregnancy, those diagnosed in their third trimester of pregnancy and those who did not develop GDM
\end{abstract}

\begin{tabular}{|lccc|}
\hline & GDM $_{\mathbf{1}}$ & $\mathbf{G D M}_{\mathbf{2}}$ & Non-GDM \\
Weight gain $(\mathrm{kg})$ & 9.6 & 12.7 & 12.4 \\
Mean $(95 \% \mathrm{Cl})$ & $(6.9-12.3) \dagger$ & $(11.0-14.4)$ & $(11.9-12.9)$ \\
Gestational Age (weeks) & 37.7 & 38.2 & 38.7 \\
Mean (95\% Cl) & $(37.0-38.4) \dagger$ & $(37.5-38.8)$ & $(38.6-38.9)$ \\
Newborn weight (g) & 3235 & 3381.2 & 3334.4 \\
Mean (95\% Cl) & $(3019-3451)$ & $(3149-3613)$ & $(3281-3388)$ \\
Newborn height (cm) & 48.9 & 50.0 & 49.4 \\
Mean (95\% Cl) & $(47.9-49.8)$ & $(49.0-51.0)$ & $(49.2-49.7)$ \\
Complications of the newborn & $22.9 \%$ & $28 \%$ & $17.6 \%$ \\
\hline
\end{tabular}

$t p<0.01$ when comparing with non-GDM. GDM : Gestational diabetes diagnosed at second trimester of pregnancy. $\mathrm{GDM}_{2}$ : Gestational diabetes diagnosed at third trimester of pregnancy.

and GDM women diagnosed in second trimester of pregnancy showed significant differences in education, age, BMI, basal glycaemia and HOMA. GDM women diagnosed in second trimester of pregnancy were less educated $(\mathrm{p}=0.036)$, older $(\mathrm{p}=0.0008)$, had more previous pregnancies $(\mathrm{p}=0.004)$ and had a higher body mass index $(\mathrm{BMI})$ in the pre-pregnancy stage $(\mathrm{p}=0.028)$ and in their first antenatal control $(\mathrm{p}=0.0007)$ than non-GDM women. The number of previous pregnancies was no longer different after adjusting by maternal age $(\mathrm{p}=0.15)$. BMI at pre-pregnancy state and at recruitment were no longer different between GDM at second trimester of pregnancy and non-GDM women after adjusting by age in logistic regression $(p=0.08)$. In the stepwise logistic regression only age and glycaemia at recruitment were independent predictors of developing GDM in second trimester of pregnancy. The only significant difference between women diagnosed with GDM in their third trimester of pregnancy and non-GDM women was that the formers had a higher percentage of family history of type $2 \mathrm{DM}(44.4 \%$ vs $22.6 \%, \mathrm{p}=0.04)$ and this was independent from age and BMI with an OR of 2.7 (95\% CI $1.2-6.0$ ).

Regarding outcomes at delivery, no significant differences were found among the groups in birth weight or height. Newborns from GDM mothers had more complications than babies from non-GDM mothers, but this difference was not statistically significant. Delivery outcomes are shown in Table 2. Women diagnosed with GDM in second trimester of pregnancy gained less weight than non-GDM women ( $\mathrm{p}=0.0026)$ and had smaller gestational age than non-GDM women $(\mathrm{p}=0.0001)$. The association between weight gain and GDM development in the second trimester of pregnancy was independent of maternal age, BMI, glycaemia, insulinaemia and HOMA at recruitment $(\mathrm{p}=0.026)$. No difference was found between GDM women diagnosed during third trimester of pregnancy and non-GDM women regarding delivery outcomes. Although these women presented more complications than GDM women diagnosed earlier and with non-GDM women, this difference was not significant.

\section{Discussion}

In this analysis of a cohort of women followed to diagnose GDM we found that those GDM women diagnosed during the third trimester of pregnancy have different risk factors than women diagnosed earlier in pregnancy. In this study, women diagnosed in second trimester are older than non-GDM women, present a higher BMI previous to pregnancy and in their first antenatal visit and have higher fasting glycaemia, higher insulinaemia and higher insulin resistance measured through HOMA. Age, weight and glycaemia are known risk factors for $\mathrm{GDM}^{12}$ and they could explain GDM development early in pregnancy. However 
in this cohort, $35 \%$ of GDM women developed this disease in their third trimester of pregnancy and they did not differ in recognised risk factors from non-GDM women. The lack of recognised risk factors could mean that these women have unknown risk factors that are probably not as strong as the known ones. This could also explain why these women manifest GDM in later stages of pregnancy. Other possibility is that these women are developing a physiologically different GDM. These women were not as insulin resistant early in pregnancy as the ones that develop GDM in second trimester of pregnancy. Therefore, they could be developing diabetes with predominance in beta cell failure over insulin resistance, resembling type $1 \mathrm{DM}$. However, it is remarkable that these women are more likely to have a family history of type $2 \mathrm{DM}$. The relationship between family history of type 2 DM and GDM has been described in a large cohort of Sardinian women in whom GDM could not be predicted by recognised risk factors ${ }^{13}$. This relationship has also been shown in a cross sectional study in 1414 GDM women and 1011 controls in which the highest associations were with prior GDM and family history of Type $2 \mathrm{DM}^{14}$. In contrast, a study on $90 \mathrm{GDM}$ women with family history of type $2 \mathrm{DM}$ and 83 women without family history of type $2 \mathrm{DM}$ showed that recognised risk factors predict better GDM in women with family history of type 2 $\mathrm{DM}^{15}$. A recent study that compares women with GDM diagnosed in the second trimester, GDM diagnosed in the third trimester and non-GDM women did not found differences among the three groups, except that GDM women diagnosed later in pregnancy had higher BMI (16). However, this study analyzed only women at high risk for GDM with a prevalence of GDM of $72 \%$ and is therefore not comparable to our study. The smaller weight gain in women who developed GDM earlier in pregnancy could be explained by the fact that they were at high risk for GDM and diet to diminish that risk.

On the other hand, characteristics on delivery were not different between GDM women diagnosed late in pregnancy and non-GDM women, while GDM women diagnosed in second trimester of pregnancy delivered earlier their babies. This could be explained by different criteria used by the gynaecologist at the moment of planning the deliveries, since they were aware of the GDM con- dition of women diagnosed earlier. Other studies demonstrate that complications are not higher in GDM when women are treated intensively for their disease ${ }^{16}$. One of the factors that justify the diagnosis of GDM is the risk to the child and in this cohort we could not demonstrate this risk, probably because of the limited number of GDM women.

\section{Conclusion}

GDM women diagnosed in second trimester of pregnancy are older and have higher fasting glycaemia and insulinaemia than women diagnosed with GDM in their third trimester of pregnancy. Women diagnosed later in pregnancy are not different from non-GDM women, but have more family history of type 2 DM. Larger studies should analyze these apparently two different populations of GDM women to estimate the costs and benefits of diagnosing GDM in late pregnancy.

Acknowledments: The study was funded by the Wellcome Trust. We are grateful to all the nurses and nutritionists working at Catholic University of Chile who made possible the development of this project.

\section{References}

1. Jovanovic L, Knopp R, Kim H, Cefalu W, Zhu X, Lee Y, et al. Elevated pregnancy losses at high and low extremes of maternal glucose in early normal and diabetic pregnancy: evidence for a protective adaptation in diabetes. Diabetes Care 2005; 1113-7.

2. Schmidt M, Duncan B, Reichelt A, Branchtein L, Matos $\mathrm{M}$, Costa $\mathrm{F}$, et al. Gestational diabetes mellitus diagnosed with a 2-h 75-g oral glucose tolerance test and adverse pregnancy outcomes. Diabetes Care 2001; 24: 1151-5.

3. Jensen DM, Sorensen B, Feilberg-Jorgensen N, Westergaard JG, Beck-Nielsen $\mathrm{H}$, et al. Maternal and perinatal outcomes in 143 Danish women with gestational diabetes mellitus and 143 controls with a similar risk profile. Diabet Med 2000; 17: 281-6.

4. Yang X, Hsu-Hage B, Zhang H, Zhang C, Zhang Y, Zhang C. Women with impaired glucose tolerance during pregnancy have significantly poor pregnancy outcomes. Diabetes Care 2002; 25: 1619-24.

5. Akhter J, Qureshi R, Rahim F, Moosvi S, Rehman A, Ja- 
Gestational diabetes, diagnosed in second and third trimester of pregnancy - A. Huidobro et al

bbar A, et al. Diabetes in Pregnancy in Pakistani Women: Prevalence and Complications in an Indigenous South Asian Community. Diab Med 1996; 13: 189-91.

6. El Mallah K, Narchi H, Kulaylat N, Shaban M. Gestational and pre-gestational diabetes: comparison of maternal and fetal characteristics and outcome. Int J Gynaecol Obstet 1997; 58: 203-9.

7. Lee A, Hiscock R, P. W, Walker S, Permezel M. Gestational diabetes mellitus: clinical predictors and long-term risk of developing type 2 diabetes: a retrospective cohort study using survival analysis. Diabetes Care 2007; 30: 878-83.

8. Lee H, Jang H, Park H, Cho N. Early manifestation of cardiovascular disease risk factors in offspring of mothers with previous history of gestational diabetes mellitus. Diabetes Res Clin Pract 2007; 78: 238-45.

9. HAPO. Study Cooperative Research Group.The Hyperglycemia and Adverse Pregnancy Outcome (HAPO) Study. Int J Gynaecol Obstet 2002; 78: 69-77.

10. McIntyre HD, Cheung NW, Oats JN, Simmons D. Gestational diabetes mellitus: from consensus to action on screening and treatment. Med J Aust 2005; 183: 288-9.

11. ADA. Gestational Diabetes mellitus (Position Statement). Diabetes Care 1998; 21(Suppl 1): S60-S1.
12. Dabelea D, Snell-Bergeon J, Hartsfield C, Bischoff K, Hamman R, McDuffie R. Increasing prevalence of gestational diabetes mellitus (GDM) over time and by birth cohort: Kaiser Permanente of Colorado GDM Screening Program. Diabetes Care 2005; 28: 579-84.

13. Murgia C, Berria R, Minerba L, Sulis S, Murenu M, Portoghese E, et al. Risk assessment does not explain high prevalence of gestational diabetes mellitus in a large group of Sardinian women. Reprod Biol Endocrinol 2008; 6: 26.

14. Ogonowski J, Miazgowski T, Homa K, Celewicz Z, Kuczynska M. Low predictive value of traditional risk factors in identifying women at risk for gestational diabetes. Acta Obstet Gynecol Scand 2007; 2: 1-6.

15. Retnakaran R, Connelly P, Sermer M, Zinman B, Hanley A. The impact of family history of diabetes on risk factors for gestational diabetes. Clin Endocrinol (Oxf) 2007; 67: 754-60.

16. Virally M, Laloi-Michelin M, Meas T, Ciraru N, Ouled $\mathrm{N}$, Médeau V, et al. Occurrence of gestational diabetes mellitus, maternal and fetal outcomes beyond the 28th week of gestation in women at high risk of gestational diabetes. A prospective study. Diabetes Metab 2007; 33: 290-5. 